УДК 81'42:55

https://doi.org/10.18485/primling.2016.17.13

\author{
Svetlana Velimirac \\ VŠSS Beogradska politehnika
}

\title{
JEZIČKA OBELEŽJA GREENSPEAK-A, ODNOSNO DISKURSA O EKOLOGIJI
}

Sažetak: Polazeći od hipoteze da je ekološki diskurs značajan element koji doprinosi očuvanju ili narušavanju životne sredine, utvrđivanje jezičkih obeležja ovog diskursa pomaže nam da utvrdimo nameru i ciljeve koje govornik želi da postigne kod slušalaca. U ovom radu predstavljene su jezičke karakteristike diskursa o ekologiji: semantičke i gramatičke odlike, neekološke pojave u jeziku, antropocentrični pogled na svet i slično. Analiza jezika u upotrebi nije ograničena isključivo na jezičku formu, nezavisnu od svrhe i funkcije jezika koji se koristi. Konteksti u kojima se jezik upotrebljava, u našem slučaju, diskursi o ekologiji, podrazumevaju i okvire unutar kojih se o ekološkim temama govori.

Ključne reči: ekologija, diskurs, jezička obeležja, priroda

Analiza diskursa podrazumeva sagledavanje jezika kao društvenog fenomena u kome je naglašena uloga govornika i slušaoca, odnosno pisca i čitaoca. Razumevanje jezika u upotrebi, u ovom slučaju, diskursa o ekologiji, počinje identifikovanjem jezičkih obeležja karakterističnih za ovu vrstu diskursa. Ne postoji jedinstvena definicija diskursa; ona, prema Stabsu, tumači „diskurs kao jezik iznad rečenice i iznad klauze” (Stubbs 1983: 1), ali mora se uvek uzeti u obzir njegova komunikativna uloga i kontekst u kome se on ostvaruje. Kontekst u kome se jezik upotrebljava, u našem slučaju, greenspeak - diskurs o ekologiji, podrazumeva okvire unutar kojih se govori o ekološkim temama. Ukoliko pored lingvističke analize uzmemo u obzir i širi, kulturni, ideološki, politički ili neki drugi okvir bitan za tumačenje greenspeak-a, naša analiza prerašće u kritičku analizu diskursa.

Ekologija kao tema zalazi u mnoštvo oblasti. Da bismo razumeli šta sve ekologija može da opisuje, treba da krenemo od samog nastanka ove reči: o pojmu ekologije pronalazimo podatke kod pruskog geografa, prirodnjaka i istraživača Humbolta, dok je sam termin ekologija prvi upotrebio nemački biolog Ernest Hekel u svojoj knjizi Generelle Morphologie der Organismen 1866. godine. Etimološki, ova reč potiče iz grčkog jezika - oikos, što znači dom, stanište, prebivalište, i logos - nauka. Centralna ideja ekologije jeste proučavanje interakcije svih organizama u prirodi i njihovog okruženja, kao i očuvanje i zaštita životne sredine. Međutim, ekologijom kao temom ne bave se samo biolozi, zoolozi ili botaničari - ona je i politička tema, i sociološka tema, aktuelna je u medijima, u ekonomiji, umetnosti i mnogim drugim oblastima. U skladu sa tim, postoji i mnoštvo 
diskursa o ekologiji. Prema Hereju, Brokmareju i Milhojsleru, podelu diskursa o ekologiji možemo vršiti na: politički, reklamni, ekonomski, moralni, akademski i estetski (Harré et al. 1999: 15). Svaki od ovih diskursa razlikuje se po tome kakva je komunikacijska struktura - ko su govornici, a kome je ekološka poruka namenjena, kao i po tome koliko se ovi diskursi razlikuju sadržajno.

Prema Ferklafu, uz lingvističku analizu, diskurs se tumači i kroz interpretativni okvir kome pripadaju učesnici diskursa. Slušaoci, ili primaoci poruke koja im je upućena, tumače i interpretiraju tu poruku, sagledavajući situacioni kontekst. Da bi se interpretirao situacioni kontekst i tip diskursa, potrebno je utvrditi sadržaj diskursa, odnosno, aktivnost koja se opisuje, temu i njegovu svrhu; ko je sve uključen u konverzaciju, i u kakvim međusobnim odnosima: utvrđujemo poziciju subjekta i društveni identitet koji subjekt ima, kao i kome se poruka upućuje, ko je prima, da li je upućena direktno ili preko posrednika itd. Što se tiče odnosa učesnika diskursa, pozicija subjekta sagledava se dinamički, u smislu odnosa moći, socijalnog raslojavanja, prirode odnosa sagovornika i sl, i na kraju, unutar analize diskursa treba da se utvrdi i uloga jezika; da li se jezik upotrebljava kao instrument u rukama institucija, na koji način je određen žanrovski, da li je u pitanju govorni jezik, napisani tekst itd. (Fairclough 1989: 147-148).

\section{Diskursi Greenspeak-a}

U diskursima kojima je tema ekologija najčešće se skreće pažnja na negativne posledice koje industrijsko društvo ima po prirodu i živi svet na Zemlji. Kako su industrija i proizvodnja, profit, ekonomija i politika u središtu ljudskog mišljenja i delanja u sadašnjem društvenom uređenju, diskurs koji se suprotstavlja ovakvoj postavci u društvu poprima različite oblike. Drajzek piše o strukturisanom načinu govora, razmišljanja, interpretiranja i prezentovanja stvarnosti kroz različite diskurse. On tvrdi da postoji set diskursa koji se upotrebljavaju u „politici planete Zemlje“, oni su u interakciji i imaju ulogu u tzv. ekološkoj demokratiji (Dryzek 1990: 20). Istovremeno, različiti ekološki diskursi često su u konfliktu: ,svaki diskurs počiva na pretpostavkama, sudovima i raspravama koji nam nude osnovne pojmove za analizu, debatu, saglasje i nesuglasice u oblasti ekološke misli baš kao i u drugim oblastima“ (Dryzek 1997: 8). U jednom diskursu, na primer, Zemlja je predstavljena konceptom živog organizma (Zemlja - Gea, mit.), dok je u drugom priroda samo gruba materija.

Ekologija kao važna društvena tema koja utiče na živote svih ljudi javlja se u različitim formama i pod različitim nazivima. Frandsen i Johansen navode da su duh vremena pred kraj dvadesetog veka različiti autori pokušali da predstave različitim nazivima kao period „ekološkog prosvetljenja“ (Beck 1989), ,prirodnu/eko epohu“ (Jakobsen 1998) ili „zeleni period“ (Harrison 1994). Samim tim, javila se i nova vrsta komunikacije sa novim žanrovima i novom retorikom, i dva karakteristična tipa diskursa: politički zeleni diskurs i reklamni zeleni diskurs (Frandsen and Johansen 2001: 57).

Politički zeleni diskurs, kako navode Frandsen i Johansen, može biti direktan ili indirektan, u različitim formama - od debate o životnoj sredini, zagađenju ili dobrobiti živih bića na Zemlji, preko književnih tekstova kao što je roman Valden H. D. Toroa, do političkog eseja Save the Planet koji je napisao Al Gor (Frandsen and Johansen 2001: 57).

U drugom, reklamnom zelenom diskursu, obuhvaćeni su tekstovi kompanija napisa- 
ni sa namerom da oglašavaju zelene proizvode ili da stvore sliku o svojoj kompaniji kao o ekološki svesnoj, i to predstavljaju kroz liniju eko-proizvoda, tekstova na ambalažama proizvoda, reklamama, brošurama o radu kompanije, godišnjim izveštajima i na internet sajtovima. Sve veći broj potrošača koji kritički posmatraju proizvode doveli su do učestalosti zelenog reklamnog diskursa. Zeleni marketing tako postaje značajna vrsta reklama. U reklamnom diskursu interakcija teksta i slike veoma je važna, tako da slušalac/gledalac/primalac poruke dekodira tekst uz pomoć slike koja ga prati. Često, u reklamama se koriste strategije kojima se uspostavlja veza između primaoca ekološke poruke i onoga ko tu poruku šalje. Jedna od tipičnih strategija je korišćenje inkluzivnog MI, ili direktnog obraćanja, TI, u porukama poput ,Mi moramo zajedno da radimo na očuvanju okoline... Priključi se i ti... Svi imamo odgovornost prema mladim naraštajima... Zarad naše budućnosti i budućnosti naše dece.“ Time se fokus prebacuje na primaoca poruke (Frandsen and Johansen 2001: 57).

Drajzek, sa druge strane, nabraja čak osam različitih diskursa u kojima se navode argumenti protiv industrijalizacije, njenog diskursa i posvećenosti neograničenom rastu u robi i uslugama kao sastavnom delu „kvalitetnog života“ (Dryzek 1997: 12). Drajzek je razvio i taksonomiju ovih diskursa, vodeći se podelom na dve dimenzije: jednu dimenziju predstavlja stepen u kojem protivnici industrijalizacije žele da se udalje od uslova života koje industrijalizacija kreira, i takvi diskursi su radikalni ili reformistički. Druga dimenzija definiše karakter alternativnih uslova života koji se predlažu, a takvi diskursi su imaginativni i prozaični. Ovi potonji koriste ,političko-ekonomsku šahovsku tablu koju je postavilo industrijsko društvo i koju predstavlja kao podrazumevano uređenje“ (Dryzek 1997: 13) dok imaginativni ,pokušavaju da tu šahovsku tablu redefinišu“ (Dryzek 1997: 13). Ove dve dimenzije formiraju četiri kategorije ekološkog diskursa: diskurs čiji je cilj rešavanje problema, diskurs opstanka, diskurs održivosti i diskurs zelenog radikalizma.

Sam pojam diskursa Drajzek razume kao „zajedničko viđenje sveta“ (Dryzek 1997: 8) i on se ogleda u pričama koje grade specifični strukturni elementi. Neki od ovih elemenata su pretpostavke o odnosima u prirodi, motivi, ključne metafore, retorički elementi i sl. Efekti koje ovi diskursi izazivaju su formiranje okvira za debate u kreiranju ekološke politike, postavljanje granica tj. određivanje „realnih“ opcija, informisanje vladajućih struktura o ekološkim problemima, informisanje javnosti itd. Karakteristike pojedinačnih kategorija ekološkog diskursa prema Drajzeku su sledeće:

1) Diskursi čiji je cilj rešavanje problema: u zavisnosti od toga koga smatramo zaduženim za nadgledanje ekološke politike - eksperte, narod ili tržište, dele se na administrativni racionalizam, demokratski pragmatizam i ekonomski racionalizam. Zagovornici koji se služe ovim diskursima smatraju da ekonomsko-politički status kvo industrijalizacije treba menjati i da u tome treba biti pragmatičan. Oni tvrde da u postojeće društveno-ekonomske strukture treba integrisati ekološke principe.

2) Diskurs opstanka preispituje dobrobiti ekonomskog prosperiteta i odnos raspodele moći. Glavni problem koji se potcrtava u ovom diskursu jeste da će ljudi „potrošiti planetu“, iscrpsti sve resurse, dovesti do izumiranja biljnog i životinjskog sveta i da će se zagađenje samo povećavati. Oni rešenje vide u ograničavanju industrijalizacije, pojačanoj kontroli i odlukama koje bi se oslanjale na naučna istraživanja.

3) Diskurs održivosti pre svega za svoje teme ima ideju održivog razvoja i ekološke modernizacije.

4) Diskurs zelenog radikalizma Drajzek dalje deli na zeleni romantizam i zeleni 
racionalizam, u kojima se odbacuju dobrobiti industrijskog društva. Pogled na prirodu, odnos čoveka i njegove okoline i samog ljudskog društva radikalniji je nego kod drugih diskursa. Različiti društveni pokreti, ali i ekološki orijentisani politički krugovi upotrebljavaju ovaj diskurs, a u njih spadaju bioregionalizam, ekofeminizam, socijalna ekologija i sl.

\section{Greenspeak i njegove osnovne karakteristike}

Greenspeak označava govor ljudi i organizacija koji se zalažu za očuvanje prirodnih resursa i unapređenje životne sredine. Ovaj diskurs bavi temama ekologije koje za cilj imaju promovisanje karakterističnih, ,zelenih“ ideja u govoru, ali veoma često mogu da imaju i prikrivene namere da se zapravo izbegnu ili odlažu konkretne delatnosti koje bi vodile očuvanju životne sredine zarad ekonomske dobiti ili nekontrolisanog korišćenja resursa (Mühlhäusler \& Peace 2006: 467). Herej, Brokmarej i Milhojsler definišu greenspeak na sledeći način:

Greenspeak predstavlja labav skup dijalekata koje bismo mogli nazvati 'jezikom životne sredine' sâme: greenspeak [podrazumeva] čitavu skalu lingvističkih sredstava usmerenih ka podizanju svesti o pitanjima životne sredine u okviru različitih diskursa koji se kreću od radikalnih do konzervativnih. (Harré et al. 1999: 2)

Knjiga o diskursu greenspeak-a navedenih autora počinje naglašavanjem da je jezik najznačajniji alat u ljudskom poimanju značenja. Putem jezika mi razumemo okruženje u kome smo i razgovaramo o pitanjima zagađenja i zaštite životne sredine. „Načini na koje se pitanja životne sredine mogu predstavljati podrazumevaju pisanu, govornu ili slikovnu formu" (Harré et al. 1999: VII). Autori zaključuju da vokabular koji se upotrebljava u diskursu greenspeak-a nije velik, a da gramatičke strukture, npr. u engleskom jeziku, ograničavaju potencijalni razvoj ovog diskursa. Kao rezultat toga, autori upozoravaju, često su debate koje se vode o ekološkim pitanjima neproduktivne. Za greenspeak, tipična je upotreba pre svega metafore, narativne strukture koja ne mora da bude hronološka, retoričkih sredstava u predstavljanju naučnih rezultata, i stilskih figura - tropa kojima se iskazuju stavovi o prirodi i čovekovoj okolini. Autori naglašavaju da je ton koji se upotrebljava u okviru ovog diskursa apokaliptičan, $\mathrm{i}$ često su predstavljene globalne razmere problema koji se opisuju. Autori navode dva aspekta greenspeak-a: temporalni i prostorni.

Temporalni aspekt - „Greenspeak je, pre svega, teleološki diskurs. Budućnost i prošlost su predstavljene kao imanentne u sadašnjosti“ (Harré et al. 1999: 7). O teleološkom jeziku kojim se iskazuju neteleološki koncepti govore i Kilinsvort i Palmer, naglašavajući da je ton koji se koristi u ekološkom diskursu „hladan, suvo objektivan, antiseptičkog pogleda na smrt i neprijatnost, sa upornim korišćenjem pasiva da bi se izbegao osećaj odgovornosti“ (Mühlhäusler and Peace 2006: 463), ali navode i da je najčešći fokus ekološkog diskursa usmeren na lokalni nivo problema, i da se tiče uglavnom problematike koja je vremenski u okviru ljudskog života pojedinca.

Prostorni aspekt - „Globalizacija diskursnih žanrova je jedna od najupečatljivijih rezultata tehnologije dvadesetog veka" (Harré et al. 1999: 12). I Jung naglašava koliko 
je važna svest o sagledavanju sveukupnih ekoloških problema u javnosti: „Društvena i ekološka svest formiraju se zajedno putem javnog diskursa, u kome jezik nije spoljašnje i proizvoljno sredstvo za prenošenje misli nezavisnih od jezika, već jezik ima snažan uticaj na to kako misao nastaje i šta se zapravo prenosi.“ (Jung 2001: 271).

Na lokalnom ili globalnom nivou, greenspeak, odnosno diskurs o ekologiji obuhvata veoma širok opseg tema: od protivljenja zagađenju vode, vazduha i zemljišta, izgradnji brana, nuklearnih postrojenja i industrija, davanja saglasnosti da se prirodne celine pretvaraju u sportske terene ili tržne centre, preko akcija za čišćenje reka, priobalja i gradova, zaštite biljnog i životinjskog sveta od izumiranja do članaka o genetski modifikovanoj hrani sa bombastičnim naslovima o mutaciji gena, ali i tvrdnji političara kako preterani strahovi koče razvoj i napredak privrede, a samim tim i države jedne nacije.

\subsection{Jezička obeležja diskursa o ekologiji}

Analiza ekološkog diskursa ili načina na koji se jezik upotrebljava da bi se o ekološkim temama govorilo i pisalo bila je predmet mnogih istraživanja. Ona su nastojala da utvrde obeležja ovog diskursa kroz proučavanje literature o ekološkim temama, novinske članke, političke govore, izlaganja na skupovima aktivista za očuvanje životne sredine i medijskih sadržaja koji prenose ekološke poruke kroz reklamiranje proizvoda i usluga neškodljivih po životnu okolinu. Mnogi autori istražuju u svojim radovima ulogu jezičkog sistema u oblikovanju svesti ljudi o pitanjima ekologije. U njima je često prisutna Sapir-Vorfova hipoteza da je percepcija realnosti određena našim misaonim procesima, a da na njih utiče jezik kojim se služimo. Na taj način, jezik oblikuje našu realnost. Tako se javlja ideja da su leksikon i gramatika pojedinačnih jezika u suštini problema ekološke krize u kojoj se svet nalazi (Mühlhäusler and Peace 2006: 468). Zbog toga, potrebno je tragati za ekološki svesnim i podesnim diskursom, i jezikom koji ne bi u centar sveta postavljao čoveka već umesto antropocentričnog, razvio biocentričan, ili ekocentričan način opisivanja stvarnosti.

Antropocentrični pogled na svet podrazumeva da je čovek centralna figura na planeti, a životinje, biljke, čitav prirodni sistem koji ga okružuje postoji zarad eksploatacije od koje korist ima čovek. Kako su mnogi autori već napominjali (npr. Halidej, Goutli) neekološki elementi i antropocentrizam ogleda se i u jeziku kojim govorimo (Fill 2001: 64). Halidej ilustruje neekološke fenomene u jeziku kao što su upotreba nebrojivih imenica kojima se sugeriše da su resursi koje koristimo neograničeni, preterano korišćenje nominalizacije ili uvođenje semantike i sintakse iz drugog jezika (Halliday 2006: 178). Kroz jezik, mi formiramo pogled na svet u kojem živimo, jezik određuje i granice našeg sveta, jezik stvara i kategorije u našem svetu koje takođe služe kao granice. Dualizam priroda/divljina nasuprot kulturi i prosvećenosti dovela je do niza aktivnosti koje su imale političke, religijske i jezičke konsekvence po narode koji se nisu uklapali u idejne okvire prosvećenog Zapada. Sa druge strane, kada se govori o „plemenitom divljaku“ (eng. noble savage) u literaturi 17. i 18. veka, idealizuje se koncept ,neiskvarenosti“ civilizacijom, dobrodušnost urođena čoveku. Da li ćemo divljinu, neukroćenu i nesputanu prirodu da percipiramo kao pozitivnu ili negativnu osobinu, kao nešto čemu težimo ili nešto što treba da iskorenimo, zavisi od toga na koji način je predstavljamo kroz diskurs.

Govoreći o Zemlji ili o prirodi kao majci (majka Zemlja, majka priroda), potvrđuje se ideja antropocentrizma: od Zemlje i prirode imamo brojna očekivanja, koristimo 
ih za svoje potrebe, one nam daju ne očekujući ništa zauzvrat, tretiramo ih kao da imaju neograničene resurse da se zadovolje sve naše potrebe, ne očekujemo da će da povrede čoveka (prirodne nepogode i nesreće uvek iznenade čoveka), a čovek smatra da ne mora ništa da im učini za uzvrat. Međutim, skretanjem pažnje na to da je realna slika potpuno suprotna ovom viđenju, da su resursi na Zemlji ograničeni, a da je obim zagađenja narušio prirodni sklada, pokrenute su brojne aktivnosti. Ekološki diskurs predstavlja sredstvo kojim se menja svest čoveka o njegovom mestu, ali i uticaju i posledicama po prirodu i Zemlju (Fill and Mühlhäusler 2001:263).

Milhojsler utvrđuje da jezik kojim se govori o temama vezanim za životnu sredinu i ekologiju karakterišu tri osnovne odlike (Mühlhäusler and Peace 2006: 468) koje doprinose smanjenom nivou međusobnog razumevanja u ekološkom diskursu:

1) semantička neodređenost; 2) nedovoljna semantička definisanost; 3) enkodiranje koje navodi na pogrešne zaključke:

1) Semantička neodređenost podrazumeva upotrebu pojmova kojima ne možemo precizno da utvrdimo obim značenja; Milhojsler navodi primere učestalih pojmova iz ekologije (eng. pollution, progress. - zagađenje, napredak) koje u ekološkom diskursu nisu precizno definisane (Mühlhäusler and Peace 2006: 468). Kako su semantičke promene deo uobičajene evolucije jezika, ali ne menjaju nužno celokupno osnovno značenje neke reči, ovakvim nepreciznostima podložne su i reči koje su tipične za greenspeak.

2) Nedovoljnu definisanost termina u ekološkom diskursu Milhojsler ilustruje pojmom iz engleskog jezika - growing, koji može da se odnosi na prirodni rast i prirodni priraštaj, zatim rast koji je uzrokovan ljudskim faktorom, eksponencijalni rast itd. (Mühlhäusler and Peace 2006: 468).

3) Enkodiranje kao oblikovanje informativnih sadržaja u poruku predstavlja proces u kom pošiljalac svoje misli, ideje i pojmove prenosi drugima. Najznačajniji trenutak ovog procesa je prevođenje određene ideje ili sadržaja u odgovarajući simbolički ekvivalent. Enkodiranje je početna faza nastajanja poruke, tako da neodgovarajuće enkodiranje ne može da dovede do adekvatnog dekodiranja poruke tj. jasne interpretacije, razumevanja, prihvatanja ili odbijanja poruke. Primer ovakvog enkodiranja je sintagma ušteda rada (Mühlhäusler and Peace 2006: 468) jer je nejasno na koga se odnosi rad, a ko ostvaruje uštedu. U diskursu greenspeak-a, namerno navođenje na pogrešno dekodiranje česta je strategija koja ima za cilj umirivanje javnosti, ublažavanje reakcija pojedinaca ili institucija, pokušaj otklanjanja odgovornosti i slično.

\subsection{Semantičke i gramatičke odlike ekološkog diskursa}

Najuočljivije jezičko obeležje ekološkog diskursa je izbor leksike. Većina autora slaže se da leksiku ekološkog diskursa karakteriše:

- morfološka kompleksnost;

- upotreba pojmova u čijem su korenu najčešće reči latinskog ili grčkog porekla;

- ograničena transparentnost pojmova;

- izbor leksike koji navodi slušaoca na pogrešne zaključke. 
Takođe, treba imati u vidu da pojmovi koji su u upotrebi u svakodnevnom diskursu, u nekim slučajevima imaju specifično značenje u ekološkom diskursu (npr. [ekološki] incident).

Tramp govori o fenomenima koji se javljaju u ekološkom diskursu. Veoma je česta reifikacija, odnosno pripisivanje konkretnih osobina nečemu što je apstraktno. Tako da čujemo kako se „majka priroda pobrinula“ za nešto ili oko nečega, iako je priroda apstraktan pojam. Zatim, živa bića tretiraju se u skladu sa ekonomsko-tehnološkom ideologijom i nad njima se vrši optimizacija, menadžment ili proizvodnja, a one same postaju materijal. Zemljište takođe podleže lingvističkoj reifikaciji kada se ono planira, dizajnira, naziva zelenim pojasom i sl. (Trampe 2001: 238).

Sledeći fenomen je korišćenje eufemizama ili pak, skrivanje činjenica. S obzirom da je uništavanje životne sredine osetljiva i neprijatna tema, upotrebom eufemizama u ekološkom diskursu nastoji se da se bar verbalno ublaže određene pojave. Umesto upotrebe reči koja bi naglasila zagađujuće efekte pojedinih grana industrije, koristi se pojam „prljave“ tehnologije/industrije, implicirajući da ne postoji neka velika opasnost, ili kako Tramp navodi, „lingvističko predstavljanje stvarne opasnosti izostaje“ (Trampe 2001: 234). Sledeći eufemizam na koji nam Tramp skreće pažnju je sintagma zagađenje životne sredine - environmental pollution, jer ova fraza implicira da su uslovi u prirodi koja nas okružuje nešto što je samo fizički oko nas, dok je realna situacija upravo suprotna. Iz perspektive se gubi da smo mi deo prirode, i da je ona deo nas. Sama fraza ,svet oko nas“ zapravo bi trebalo da glasi „svet sa nama“" (Trampe 2001: 234) jer samo u suživotu sa prirodom ljudska vrsta može da opstane. Tipična rečenica koja se čuje u ekološkom diskursu glasi „Mi moramo da održavamo životnu sredinu čistom“ (Trampe 2001: 234), što se zapravo ne odnosi na čišćenje i čistoću u osnovnom značenju te reči, već se misli na očuvanje prirodnih potencijala da mogu da nastave da se razvijaju i da se održe i u budućnosti. Takođe, Tramp naglašava, umesto reči otrov koriste se blaže varijante - pesticid, biocid ili, čak, sredstvo za zaštitu bilja. Kada se tone prehrambenih proizvoda uništavaju, to nazivamo uklanjanjem s tržišta. Mešavine različitih, često opasnih materija nazivaju se koktelima, a pod klasom kvalitetnih proizvoda, npr. voća i povrća, kvalitet se često ogleda u spoljašnjem izgledu, boji ili ujednačenoj veličini plodova, a ne stvarnoj nutritivnoj vrednosti ili odsustvu neželjenih materija (Trampe 2001: 238).

Jung govori o pomeranju termina karakterističnim za pojedine oblasti i njihovom pozicioniranju u ekološkom diskursu. Iz oblasti nuklearne energije u opšti, svakodnevni diskurs ušle su pojedine fraze i reči: Jung navodi primer sintagme odlaganje otpada (eng. waste disposal) koja se tipično pojavljivala kao fraza administrativne komunalne terminologije šezdesetih godina dvadesetog veka, da bi zatim ušla u terminologiju diskursa o atomskoj energiji, a odatle u opšti diskurs o životnoj sredini (Jung 2001: 279).

Lejkof daje primer kako je jedan memorandum F. Lunca upućen Bušovoj administraciji 2003. godine uticao na zamenu fraze „globalno zagrevanje“ u manje zastrašujuću - „klimatske promene“:

Ideja je bila da reč „klimatske“ ima prijatnu konotaciju - više podseća na njihanje palmi nego na poplavljene priobalne gradove. Rečju ,promene“, izostavljen je ljudski faktor koji je ovome doprineo. Jednostavno, klima se promenila. Niko nije kriv. (Lakoff 2010: 71)

Goutli ističe nastojanja da se nominalizacijom smanji naglašavanje pozicije ugro- 
ženih u tekstovima o životnoj sredini. Primer ovakve upotrebe bili bi tekstovi o lovu, pri čemu se životinje nad kojima se vrši ova aktivnost uopšte ne pominju, već se isključivo navode nominalne grupe: a slaugtering operation, killing methods, killing techniques, a humane death. Sa druge strane, ugroženi mogu biti pomenuti, ali samo u funkciji modifikatora u rečenici: the seal hunt, the whitecoat harvest (u značenju - lov na foke). Ferklaf ističe primere kada subjekat u rečenici postaje neživa stvar, čime se uklanja iz teksta vršilac radnje i njegova odgovornost: Lorries shed their loads. (Goatly 2001: 220). „Kamioni koji su istovarili“" ne daju nam uvid u ljudski faktor koji je zapravo prouzrokovao problem neodgovornog odlaganja otpada. Pojmovi kao što su degradacija, destrukcija, oštećenje (eng. degradation, destruction, depletion) navode čitaoca da je agent radnje - svi ljudi, a ne pojedinačne institucije ili korporacije koje prednjače u narušavanju životne sredine (Goatly 2001: 229).

„Bili mi svesni toga ili ne, lingvističko ponašanje funkcioniše kao snažan i podmukao mehanizam u kreiranju i očuvanju hijerarhije moći, stalno umanjujući kontrolu koju drugi imaju, uključujući i druga živa bića“ (Kahn 2001: 241). Seksizam u jeziku doprinosi degradaciji i potčinjenom položaju žena, ali na isti način možemo da proučimo i jezički šovinizam uperen protiv drugih živih bića. Autorka Kan naglašava da je naučna literatura puna jezičkih navika i lingvističkih markera koji doprinose ovoj pojavi. Jedna od najuočljivih je upotreba pasivnih konstrukcija u kojima ne znamo ko je počinilac ili vršilac radnje. Ova pojava je veoma prisutna u ekološkom diskursu. Time se gubi naš uvid u odgovornost onoga ko je doveo do određenih posledica, na primer, vršenjem eksperimenata nad životinjama. Vršioca zamenjuje sama radnja, koja se naizgled odigrala sama po sebi, bez uticaja spoljašnjih faktora - čoveka. Kao i prethodni autori, i Kan naglašava da su upotreba eufemizama, pasivne konstrukcije i predstavljanje živog bića koje nije čovek kao nežive stvari tipične u diskursu ekologije, pogotovo u naučnom ekološkom diskursu. Karakteristična jezička obeležja koja ona izdvaja su sledeća:

- odsustvo upotrebe ličnih zamenica i prebacivanje naglaska na objekat u rečenici: „Testiranim životinjama obezbeđeno je 500 grama suve hrane jednom dnevno... Reakcije životinja su praćene na svaka četiri sata do trenutka uginuća ili oporavka, koje je, za svrhu ove studije, smatrano postignutim ukoliko... “ (Kahn 2001: 242);

- zamena termina onima koji su blaži, prijatniji uobičajena je, tako da sve životinje nad kojima se vrše ogledi jednim nazivom postaju test animals, a same radnje koje se nad njima obavljaju zvuče manje surovo. Ubijanje određenih životinjskih vrsta naziva se kontrolom, zatim, nasilno premeštanje životinje u novo stanište je relokacija, a lov je u engleskom jeziku u određenim kontekstima zamenjen rečju žetva (npr. eng. fish harvest, elk harvest) (Kahn 2001: 243).

Etičko preispitivanje postupaka prema prirodi, biljnom i životinjskom svetu umanjeno je lingvističkim strategijama koje određeni govornici upotrebljavaju, i time utiču na kognitivno poimanje takvih postupaka. Veoma je interesantan u engleskom jeziku lingvistički prelaz obraćanja životinjama sa thou na it u trećem licu jednine, navodi Kan. Thou implicira živo biće, pa i sve oblike života kao vredne poštovanja, dok bezlično it $\mathrm{u}$ sebi nosi naglasak na odsustvo ljudske forme, odsustvo svesti, nečega čime se koristimo i čime upravljamo u zavisnosti od naše volje. (Kahn 2001: 243). 


\section{Eko-manipulacija u diskursu Greenspeak-a}

U diskursu politike i medija veliki značaj pridaje se načinu na koji se govori o ekološkim temama zbog buđenja svesti glasača, gledalaca i potencijalnih potrošača o problemima po okolinu i zdravlje ljudi. Kompanije pokušavaju da se u medijima predstave kao prijatelji prirode, tako da svoje proizvode reklamiraju kao neškodljive, zelene, organske i sl. Fil je pratio učestalost pojavljivanja zelenih reklama u magazinima Tajm i Njuzvik tokom određenog vremenskog perioda, i rezultati njegovog istraživanja pokazuju da je broj takvih reklama bio u stalnom porastu od 1970. godine do '90-ih godina 20 . veka, a zatim je usledila kratkotrajna stagnacija. Ovi rezultati se poklapaju sa periodom naglog rasta interesovanja javnosti za ekološke probleme do kraja devedesetih godina dvadesetog veka (Fill 2001: 69). U diskursu ovakvih reklama primećene su različite lingvističke strategije koje se koriste kako bi proizvodi delovali ekološki prihvatljivije za kupce.

Zloupotreba ovog načina reklamiranja je u tome što se putem medija zagađujući i štetni proizvodi predstavljaju kao rezultat brižljivog rada industrija u cilju brige za čovekovu okolinu, ne pominjući štetu koju pritom nanose prirodi. Ovakve pristupe u diskursu Fil naziva površinskom ekologizacijom (Fill 2001: 71). U njima se kombinuje privlačnost tehnološki naprednog proizvoda sa greenspeak-om, a takva strategija primer je greenwashing-a, ili ekološke manipulacije. Ovakvim reklamama apeluje se na moralnu svest kupaca, ne samo da će dobiti za svoj novac savremeniji proizvod, već će istovremeno i doprineti očuvanju životne sredine. Greenwashing predstavlja manipulaciju jer izaziva ,nesigurnost u stvarnu pretnju po životnu sredinu” (Mühlhäusler and Peace 2006: 461).

Obilje zelenih reklama predstavlja odgovor na zahteve tržišta da proizvodi budu ekološki, prirodni i da ne zagađuju životnu sredinu. Pokušaj da svoje proizvode predstave na ovaj način, a svoje kompanije kao veoma zainteresovane za očuvanje prirode predstavlja veliki kontrast u odnosu na početak 20. veka kada je bilo poželjno u javnosti stvarati sliku o poslovanju kao modernom, naprednom, kao prkošenju i savladavanju prirode. (Kahn 2001: 245). Greenwashing i slikovno potencira pastoralne prikaze, reke, domaće životinje, divljinu, šume, odsustvo dimnjaka, dok su se ranije rado prikazivale scene iz fabrike koje bi upućivale na sposobnost kompanije da proizvodi i napreduje. Menjanje prirodnog pejzaža smatralo se podvigom. Sedamdesetih godina dvadesetog veka, industrijska postrojenja i dim iz dimnjaka postali su simboli zagađenja, tako da su i slikovni prikazi prešli na prikazivanje livada punih cveća, dece, ptica, zelenog lista i drveća. Izuzeci predstavljaju prikazivanja prirode kao neprijatelja, ,dobrog sluge, ali zlog gospodara" kada se reklamiraju proizvodi kao što su izolacioni materijali i sl.

Nije sama asocijacija sa prirodom u srži ovih reklama, već nastojanje da se proizvodi i same kompanije prikažu kao ,saradnici“ prirode. Sa prirodom se više ne takmiči, ne izražava se želja da se ona savlada ili pobedi, već da se sama priroda unapredi. Kompanije su svesne značaja reputacije i slike koja se u medijima o njima plasira, tako da su voljne da reklame za njihove proizvode poprime uticaj društveno prihvaćenih vrednosti, a da se te vrednosti reflektuju kroz diskurs koji je ekološki. Tako da se kompanije trude da budu ,zelene“ i na delima i na rečima, što se ogleda u predstavljanju javnosti ušteda koje one ostvaruju pri proizvodnji, odgovornom odlaganju otpada, učestvovanja u ekološkim akcijama i organizacione kulture u kojoj je „zeleni stav“ sveprisutan. (Frandsen and Johansen 2001: 60). 


\section{Zaključak}

U svojim radovima, Alan Fil postavlja pitanje: da li tekstovi o ekologiji proučavaju, trude se da očuvaju ili potpomažu iskorišćavanje prirode? Da li se u savremenim tekstovima iskazuje shvatanje o ekološkoj svepovezanosti ili su u pitanju samo vešto prikriveni -izmi i ideologije (etnocentrizam, antropocentrizam, rasizam...)? Zbog toga, teorijski pristupi diskursu uvek uzimaju u obzir društveno okruženje, okruženje koje je stvorio čovek. Prirodno okruženje i uticaj ljudi na njega samo su deo šire slike, naročito u analizi diskursa o životnoj sredini (ili njegovih zasebnih pod-diskursa). Stoga, da bismo što bolje razumeli diskurs greenspeak-a, odnosno diskursa o ekologiji, potrebno je sagledati učesnike diskursa, kontekste u kojima se javljaju i koja jezička obeležja karakterišu

ovaj diskurs. Za ekološki diskurs tipična je upotreba nominalizacije, pasivnih konstrukcija, reifikacije, eufemizama, metafore, greenwashing i sl. Sve one doprinose kreiranju određenih stavova i reakcija u javnosti prema ekološkim problemima. „Zeleni“ pristup u diskursu može pomoći u razumevanju kako lokalnih, tako i globalnih razmera problema u vezi sa životnom sredinom i živim bićima na našoj planeti. Antropocentrični pogled na svet preispituje se u smislu sagledavanja budućnosti opstanka čoveka, čovečanstva i sveukupne prirode i živog sveta na planeti Zemlji.

\section{Literatura}

Dryzek, J. S. (1990). Discursive Democracy: Politics, Policy, and Political Science. Cambridge, MA: Cambridge University Press.

Dryzek, J. S. (1997). The Politics of the Earth: Environmental Discourses. New York: Oxford University Press.

Fairclough, N. (1989). Language and Power. Longman Group.

Fill, A. (2001). Language and Ecology: Ecolinguistic Perspectives for 2000 and Beyond. AILA Review 14: 60-75.

Fill, A. and P. Mühlhäusler (2001). (eds.). The Ecolinguistics Reader: Language, Ecology and Environment. London / New York: Continuum.

Frandsen, F. and W. Johansen (2001). The Rhetoric of Green Hotels. Hermes 27: 55-83.

Goatly, A. (2001). Green Grammar and Grammatical Metaphor, or Language and Myth of Power, or Metaphors We Die By. In: The Ecolinguistics Reader: Language, Ecology and Environment (A. Fill and P. Mühlhäusler, eds.), London / New York: Continuum, 203-225.

Halliday, M. A. K. (2001). New Ways of Meaning: The Challenge to Applied Linguistics. In: The Ecolinguistics Reader: Language, Ecology and Environment (A. Fill and P. Mühlhäusler, eds.), London / New York: Continuum, 175-202.

Harré, R., Brockmeier, J. and P. Mühlhäusler (1999). Greenspeak: A Study of Environmental Discourse. Thousand Oaks, CA: Sage Publications.

Jung, M. (2001). Ecological Criticism of Language. In: The Ecolinguistics Reader: Language, Ecology and Environment (A. Fill and P. Mühlhäusler, eds.), London / New York: Continuum, 270-285.

Kahn, M. (2001). The Passive Voice of Science. Language Abuse in the Wildlife Profession. In The Ecolinguistics Reader: Language, Ecology and Environment (A. Fill and P. Mühlhäusler, eds.), London / New York: Continuum, 241-244.

Lakoff, G. (2010). Why It Matters How We Frame the Environment. Environmental Communication: A Journal of Nature and Culture 4 (1): 70-81. 
Mühlhäusler, P. and A. Peace (2006). Environmental Discourses. Annual Review of Anthropology 35: 457-479.

Stubbs, M. (1983) Discourse Analysis. Oxford: Basil Blackwell.

Trampe, W. (2001). Language and Ecological Crisis. Extracts from a Dictionary of Industrial Agriculture. In The Ecolinguistics Reader: Language, Ecology and Environment (A. Fill and P. Mühlhäusler, eds.), London / New York: Continuum, 232-240

\section{Svetlana Velimirac}

\section{GREENSPEAK LANGUAGE FEATURES, OR DISCOURSE ON ECOLOGY}

Summary: Starting from the hypothesis that ecological discourse is an important element that contributes to the preservation or degradation of the environment, identifying linguistic features of this discourse helps us determine the intent and objectives that the speaker wants to achieve with the audience. This paper presents the linguistic characteristics of ecological discourse: semantic and grammatical features, non-ecological phenomena in language, anthropocentric perspective of the world and the like. Analysis of language in use is not limited to linguistic form independent of the purpose and functions of the language used. The contexts in which language is used, in this case, discourses about ecology, include all the frames that encompass environmental issues.

Key words: ecology, discourse, linguistic features, nature 